VARIA

\title{
Hannah Arendt e a filosofia política na era atômica
}

\section{Hannah Arendt and political philosophy in the atomic age}

* Gabriel Guedes Rossatti

\begin{abstract}
Resumo: A filósofa política Hannah Arendt (1906-1975) é mundialmente conhecida como uma das principais teóricas do fenômeno do totalitarismo. Não obstante, há também como questão estrutural a atravessar seu pensamento a não menos importante questão não apenas das armas ditas nucleares (bomba atômica, bomba de hidrogênio), mas mais geralmente da ciência nuclear. Neste sentido, o presente artigo objetiva explorar, em um primeiro momento, a recepção filosófica dos acontecimentos ligados ao lançamento das primeiras bombas atômicas; num segundo, a interpretação arendtiana das questões acima aludidas para, por fim, tomando como ponto de partida a reflexão arendtiana sobre a relação entre modernidade e domínio da ciência/tecnologia atômica, pensar a nossa situação contemporânea em face de tais questões.
\end{abstract}

Palavras-chave: Hannah Arendt. Bomba atômica. Ciência nuclear. Sociedade de consumo. Processo.

\begin{abstract}
The political philosopher Hannah Arendt (1906-1975) is worldly known as one the main theoreticists on the phenomenon of totalitarianism. However, there is another object which is perhaps as important in terms of the construction of her thought, viz. not only the atom bomb more specifically, but more generally the issue of nuclear science. In this sense, the present paper seeks to investigate I) the philosophical reception to the launching of the first atom bombs; II) the arendtian interpretation of the matters advanced above and this in order to III) throw some light on our present situation in what concerns precisely the issues related to te dominion of nuclear technology.
\end{abstract}

Keywords: Hannah Arendt. Atom Bomb. Nuclear science. Consumers' Society. Process.

* Doutor em Ciências Humanas pela Universidade Federal de Santa Catarina (UFSC), Brasil. <gabrielrossatti@gmail.com>. 


\section{A recepção filosófica acerca do lançamento da bomba atômica sobre Hiroshima e Nagasaki}

$\mathrm{C}$ omo é de conhecimento comum, a primeira bomba atômica foi lançada sobre o Japão e, mais especificamente, sobre a cidade de Hiroshima, no dia 06 de Agosto de 1945; a segunda seria lançada sobre Nagasaki no dia 09 desse mesmo mês. Por volta desse momento, o Japão já buscava negociações de paz através de Moscou; seus diplomatas já visavam declarar sua rendição, a qual somente ocorreria após o lançamento da segunda bomba sobre Nagasaki. ${ }^{1}$ No que diz respeito à cidade de Hiroshima propriamente dita, viviam nesse momento lá cerca de 280.000 a 290.000 habitantes e que, diretamente por causa da bomba, cerca de 70.000 mil desses tiveram morte imediata, sendo que nos cinco anos seguintes mais uns 230.000 habitantes morreriam em decorrência de problemas causados pela radiação. ${ }^{2}$ No que diz respeito aos agressores, o presidente dos Estados Unidos Harry Truman, após o lançamento da bomba, publicamente disse que com ela entrava-se em "uma nova era do entendimento humano [acerca] das forças da natureza." 3

A primeira reação vinda de um filósofo (de renome), até onde se sabe, ${ }^{4}$ foi aquela publicada em breve artigo no jornal Combat por Albert Camus no dia 08 de Agosto de 1945. Lá ele inicia sua argumentação com as seguintes palavras:

O mundo é o que é, quer dizer, pouca coisa. Isso é o que cada um sabe desde ontem graças ao formidável concerto que o rádio, os jornais e as agências de informação acabam de lançar acerca da bomba atômica. Eles nos ensinam, de fato, em meio de uma multidão de comentários entusiasmados que não importa qual cidade de importância mediana pode ser totalmente demolida [rasée] por uma bomba do tamanho de uma bola de futebol. Jornais americanos,

1 Cf. DEMENCHONOK, Edward. "Introduction: From Power Politics to the Ethics of Peace". In: DEMENCHONOK, Edward. (Ed.). Philosophy after Hiroshima. Cambridge: Cambridge Scholars Publishing, 2009. p. 5.

2 Ibidem, p. 37, n. 3. Já o sítio eletrônico Wikipedia, em sua versão em inglês, fornece outros dados, a saber, que de dois a quatro meses após o lançamento da bomba sobre Hiroshima algo entre 90.000 a 166.000 pessoas morreram; em Nagasaki, entre 60.000 a 80.000 para um mesmo período de tempo; cf. <http://en.wikipedia.org/wiki/Hiroshima and_Nagasaki>.

3 TRUMAN apud DEMENCHONOK, Edward. "Introduction: From Power Politics to the Ethics of Peace". In: DEMENCHONOK, Edward. (Ed.). Philosophy after Hiroshima, p. 7; esta frase é importante na medida em que, como será visto, Arendt viria a desenvolver suas análises da bomba atômica como uma espécie de comentário a esta declaração; obviamente, porém, esta provavelmente apenas refletia explanações dadas por cientistas acerca da bomba. Vale também mencionar que todas as traduções são minhas, salvo indicações.

4 Cf. GAY, William C. "Nuclear Weapons and Philosophy in the Twenty-First Century: The Relevance of Initial Philosophical Responses to the Atomic Bomb". In: DEMENCHONOK, E. (Ed.). op. cit., p. 45. 
ingleses e franceses se entregam a dissertações elegantes sobre o futuro, o passado, os inventores, o custo, a vocação pacífica e os efeitos [para a] guerra, as consequências políticas e mesmo o caráter independente da bomba atômica. Nós nos resumiremos em uma frase: a civilização mecânica acaba de chegar ao seu último grau de selvageria. Será preciso escolher, em um futuro mais ou menos próximo, entre o suicídio coletivo ou a utilização inteligente das conquistas científicas. ${ }^{5}$

Como se pode ver, ecoa no artigo de Camus a recepção midiática generalizada ao lançamento da bomba sobre Hiroshima e, neste sentido, seu breve artigo se configura como uma reflexão tanto acerca do lançamento propriamente dito da bomba quanto sobre tal recepção. Ressalta, de qualquer maneira, a interpretação do fenômeno como um marco divisor de águas - em seus termos, "uma descoberta que se põe fundamentalmente ao serviço da mais formidável fúria de destruição que o homem tenha feito prova há séculos"6 - na história da humanidade e, mais especificamente, o papel da ciência em meio à forma de "civilização mecânica"; com efeito, no parágrafo seguinte Camus aponta que apenas os mais idealistas não reconheceriam que, no século XX, a ciência havia "se consagrado ao assassinato organizado". ${ }^{7}$

Mais contundentemente, porém, Camus vê na bomba atômica sendo que, entre parêntese, ele se regozija com, naquele momento, uma provável capitulação do Japão ${ }^{8}$-, por um lado, uma "angústia nova (...) [e] que tem todas as chances de ser definitiva", ${ }^{9}$ enquanto que por outro lado, ela ofereceria "à humanidade sua última chance", isto é, a decisão de lutar por uma "verdadeira sociedade internacional onde as grandes potências não terão direitos superiores sobre as nações pequenas e medianas, onde a guerra (...) não dependerá mais dos apetites e doutrinas de tal ou tal Estado." ${ }^{10}$ Em suma, Camus vê na bomba atômica uma infeliz oportunidade para se parar e pensar, senão estruturar um organização política universal baseada na paz entre as nações, pois como ele encerra seu artigo, "[n]ão é mais uma oração, mas uma ordem que deve ascender dos povos aos governantes, a ordem de escolher definitivamente entre o inferno e a razão."11

Meses após a publicação do artigo de Camus, em outubro de 1945, mais exatamente, seria Jean-Paul Sartre aquele que viria a público tecer

\footnotetext{
CAMUS, Albert. "Actuelles I (Chroniques 1944-1948)". In: CAMUS, Albert. Essais. Ed. R. Quilliot. Paris: Gallimard, 1965. p. 291.

6 Ibidem, p. 292.

7 Ibidem, p. 292.

8 Ibidem, p. 292.

9 Ibidem, p. 292.

10 Ibidem, p. 292.

11 Ibidem, p. 293.
} 
algumas considerações sobre a bomba atômica. ${ }^{12}$ Para ele, esta seria um artefato produzido pela espécie humana mas que, curiosamente, implicaria precisamente uma saída ou ultrapassagem dessa mesma ordem, dado que a espécie, pelo fato de não possuir a faculdade de escolher, estaria no nível da natureza. Em outras palavras, a bomba atômica, ao depositar sobre a espécie humana a responsabilidade sobre seu próprio destino, faria com que esta se colocasse em um outro patamar, pois como ele diz, "[n]ão há mais uma espécie humana. A comunidade que fez de si mesma a guardiã da bomba atômica está acima do reino animal, na medida em que é responsável por sua vida e por sua morte." 13

Mais especificamente, Sartre imputa tal responsabilidade não apenas à espécie enquanto tal, mas também (ou, sobretudo,) aos indivíduos (ainda que compreendidos coletivamente), pois imaginando um "novo Führer" a iniciar uma guerra nuclear, ele compreende que "por este novo Führer, tal qual o primeiro, nós todos seríamos responsáveis." ${ }^{14}$ Logo, a bomba atômica, no entender de Sartre, seria um elemento determinante a nos forçar, para além de nossa mera natureza humana, a ser livres, entendendo-se por liberdade a responsabilidade incondicional imputada a cada indivíduo. Estas, em suma, parecem ser as respostas filosóficas mais imediatas ao lançamento das bombas atômicas sobre ambas Hiroshima e Nagasaki e, se há um denominador comum para ambas, este é o seu idealismo; Camus, pensando em termos da "paz [sendo] o único combate que val[e] a pena de ser levado adiante" 15 e Sartre, por sua vez, imputando, tal qual um

12 Sigo neste ponto GAY, William C. "Nuclear Weapons and Philosophy in the Twenty-First Century: The Relevance of Initial Philosophical Responses to the Atomic Bomb". In: DEMENCHONOK, E. (Ed.). op. cit., p. 48-49. O artigo original de Sartre levava o título "La fin de la guerre", tendo sido originalmente publicado na revista Les Temps Modernes. Vale também mencionar que, em termos de respostas imediatas ao lançamento das bombas, este autor menciona apenas os artigos de Camus e Sartre, o restante de sua análise repousando sobre teorizações posteriores de ambos Bertrand Russell e John Dewey; já acerca de Arendt, ele nem sequer a menciona, o mesmo valendo em boníssima medida para a coletânea na qual seu artigo se encontra.

13 SARTRE apud GAY, William C. "Nuclear Weapons and Philosophy in the Twenty-First Century: The Relevance of Initial Philosophical Responses to the Atomic Bomb". In: DEMENCHONOK, E. (Ed.). op. cit., p. 48.

14 SARTRE apud GAY, William C. ibid., p. 48.

15 CAMUS. op. cit., pp. 292-293. No que diz respeito ao idealismo de Camus, Raymond Aron diria, a título de exemplo, que "em seu livro O Homem Revoltado [L'Homme Revolté], ainda que adotando uma posição clara contra a União Sovética, ele não tirava nenhuma conclusão de ordem diplomática. Ele jamais escreveu, até onde eu possa me lembrar, sobre a aliança Atlântica, jamais propôs de fazer isto ou aquilo (...). Já eu era muito mais político do que os outros, muito menos ideólogo, se preferirem assim" (ARON, Raymond. Le Spéctateur Engagé: entretiens avec Jean-Louis Missika et Dominique Wolton. Paris: Julliard, 1983. p. 174). 
moraliste ${ }^{16}$ a responsabilidade total a cada indivíduo, coletivamente, por cada ato de injustiça cometido na face da terra. ${ }^{17}$ Ora, resta saber como é que alguém no Brasil (ou na China, no Azerbaijão, nas Ilhas Samoa etc.) teria sido responsável pela ascensão fosse do Führer original (Hitler) a milhares de quilômetros de distância, isto é, na Alemanha, fosse do "novo Führer", aqui mesmo ao nosso lado. E ainda que neste último caso se possa dar alguma razão a Sartre, vale explicitar que a política não se dava e muito menos se dá, hoje em dia, da maneira imediatamente direta tal qual Sartre parece concebê-la e, assim, acaba sendo idealista ou ingênua ${ }^{18}$ a postura que imputa a cada indivíduo o poder de decisão total acerca da própria vida ou do próprio destino. Cabe agora ver como Arendt respondeu ao acontecimento mais amplo do desenvolvimento e domínio da tecnologia nuclear.

\section{Hannah Arendt e a era atômica}

No que diz respeito à abordagem arendtiana da bomba atômica, vale antes e acima de tudo enfatizar que se ela, por um lado, diferentemente de seu mentor e amigo Karl Jaspers, não chegou a produzir um livro ou ensaio dedicado ao tema seja da bomba atômica mais especificamente, ${ }^{19}$ seja da "era atômica" em termos mais gerais, por outro, isto não significa que ela tenha deixado de refletir sobre essas questões. ${ }^{20}$ Com efeito, a importância desta temática em termos da economia interna de seu pensamento foi reconhecida pela própria autora na medida em que, para ela, o "totalitarismo e a bomba atômica [...] são as experiências fundamentais de nossa época, e se nós as ignorarmos, seria como se jamais tivéssemos vivido no mundo que é o nosso." ${ }^{21}$ Curiosamente,

${ }^{16}$ Nas palavras de seu antigo camarada de École supérieure, Aron, "Sartre (...) era mais moralista do que político. E creio que ele geralmente se perdeu na política, precisamente porque ele era essencialmente um moralista, mas de um estilo bastante diferente do tipo habitual: um moralista invertido, um moralista da autenticidade e de forma alguma do conformismo burguês a respeito do qual ele tinha horror" (ARON, R. op. cit., p. 171).

17 Hannah Arendt, neste sentido, diria: "[n]ão há tal coisa como culpa coletiva ou inocência coletiva; culpa e inocência somente fazem sentido quando aplicadas aos indivíduos" (ARENDT, Hannah. "Personal Responsibilty Under Dictatorship". In: ARENDT, Hannah. Responsibility and Judgment. Ed. J. Kohn. New York: Schocken Books, 2003. p. 29; cf. também, no mesmo volume, "Collective Responsibility", p. 147-158).

18 Comentando a posição de Sartre, Aron diria mesmo que "não gosto de bancar a consciência universal. Acho isto indecente" (ARON. op. cit., p. 100).

19 Cf. JASPERS, Karl. Die Atombombe und die Zukunft des Menschen. München: Piper Verlag, 1958.

20 Vale explicitar que Arendt usa indistintamente os termos "bomba atômica" e "armas nucleares" e, assim, os mesmos também serão usados indistintamente por mim ao longo deste artigo.

21 ARENDT, Hannah. "Introduction into Politics". In: ARENDT, Hannah. The Promise of Politics. Ed. J. Kohn. New York: Schocken Books, 2005. p. 109-110. 
porém, a imensa maioria de estudos interpretativos acerca do pensamento de Arendt desconsidera este segundo tópico, mas como a citação bem o comprova, não há como ler nada desta autora quando não se leva em conta esta problemática. Cabe então analisar como esta questão ganhou forma em termos do desenvolvimento de seu pensamento e, mais exatamente, reconhecer no interior de suas análises acerca deste tópico as duas linhas argumentativas principais a partir das quais ela desenvolveu sua interpretação do tema. Começarei, portanto, com a primeira dessas linhas, a saber, a linha de interpretação da bomba atômica em termos de análise política das relações internacionais.

\subsection{A bomba atômica no contexto das guerras ideológicas}

No que diz respeito à bomba atômica propriamente dita, a reação mais direta da parte de Arendt se deu em um artigo publicado em Setembro de 1954, cujo título era "A Europa e a Bomba Atômica". ${ }^{22}$ Ali, pois, se por um lado Arendt reconhece o potencial destrutivo inaudito dessa nova arma de guerra, no que a bomba atômica seria "o símbolo para uma conspiração entre o homem [sic] e as forças elementares da natureza, as quais, quando desencadeadas pelo know-how humano, podem um dia reclamar sua vingança e destruir toda vida na superfície da terra e talvez a própria terra", ${ }^{23}$ por outro lado ela, analisando as relações internacionais de um ponto de vista realista, argumenta no sentido tanto da necessidade de se romper com a interpretação naïve de muitos europeus da bomba atômica como um produto exclusivo da civilização estadunidense - posto que para ela "a descoberta da energia atômica resultou largamente dos esforços de cientistas europeus forçados a vir para a América [sic]" -,${ }^{24}$ quanto no sentido de, mais especificamente, urgindo uma (vindoura ou desejável) união europeia que teria como uma de suas principais incumbências estruturar através de um sistema federalista um regime de paz para o continente no pós-guerra, ela argumenta mesmo, senão clama seus contemporâneos (europeus) no sentido de que a Europa deveria também ela possuir sua própria bomba atômica para fazer frente tanto a uma possível ameaça dos estadunidenses, quanto dos russos. ${ }^{25}$ Assim, excetuando-se uma outra linha argumentativa presente neste mesmo artigo e na qual Arendt considera os efeitos da bomba atômica

22 Cf. ARENDT, Hannah. "Europe and the Atom Bomb". In: ARENDT, Hannah. Essays in Understanding: 1930-1954. Ed. J. Kohn. New York: Schocken Books, 1994. p. 418-422.

23 Ibidem, p. 420.

24 Ibidem, p. 419.

25 Cf. ARENDT, Hannah. "Europe and the Atom Bomb". In: ARENDT, Hannah. Essays in Understanding: 1930-1954. Ed. J. Kohn. New York: Schocken Books, 1994. p. 422. 
em termos de mudança de paradigma intelectual, ${ }^{26}$ a primeira declaração pública impressa de Arendt a respeito da bomba atômica distingue-se do tipo de interpretação de ambos Camus e Sartre, como visto acima, e isto fundamentalmente pelos seguintes motivos: 1) pelo fato de, ao invés de pregar o pacifismo de índole idealista (Camus), ela pensa tal posição a partir de estruturas políticas que lhe dariam uma forma concreta e $2)$, distanciando-se igualmente da análise eminentemente moral da questão (Sartre), ela se aproxima da posição (realista) de um Raymond Aron - o qual, aliás, ela cita nesse artigo, ainda que não dando a referência precisa $^{27}$-, no que, consequentemente, encara o âmbito das relações internacionais como um jogo de forças no qual as ameaças têm de ser contrapostas através de ações de ordem eminentemente prática.

Ora, esta linha de raciocínio seria não apenas retomada mas aprofundada em sua análise, publicada como ensaio em Fevereiro de $1958,{ }^{28}$ da revolução húngara ocorrida, por sua vez, em 1956. Ali, pois, na medida em que a questão fulcral era analisar o acontecimento inesperado da revolução húngara e dado que esta ocorreu, por sua vez, como uma resposta à invasão soviética, Arendt não apenas não tinha como não discutir a política imperialista desse estado, senão que ela leva em consideração exatamente o papel que o artefato da bomba atômica desempenharia no âmbito das relações internacionais, e isto especialmente quando em mãos de uma superpotência belicosa, expansionista, em suma, imperialista, como a União das Repúblicas Socialistas Soviéticas. Deve-se lembrar que se estava em plena "guerra fria" quando Arendt escreveu este ensaio e é assim, a partir do contexto russo e, neste sentido, europeu, que Arendt investiga neste texto a relação entre a posse e eventual uso de armas nucleares, por um lado, e Estados totalitários, pelo outro.

De acordo com Arendt, portanto, em meio à guerra ideológica entre capitalismo e socialismo, as armas nucleares teriam um papel de destaque na medida em que serviriam como meio de dissuasão e de ameaça. Ela cita, neste sentido, um recém empossado Kruschev neste momento,

${ }_{26}$ Pois como ela diz, "[c]om o aparecimento de armas atômicas, ambos a tradição hebraico-cristã de limitação da violência e o apelo antigo à coragem para todos efeitos práticos tornaramse desprovidos de sentido e, com eles, o vocabulário político e moral no qual estávamos acostumados a discutir estes assuntos" (Ibidem, p. 421).

27 Cf. Ibidem, p. 421. Sobre o "realismo aroniano" em termos de relações internacionais - "[i] nfelizmente a política estrangeira é um exercício de escroques ou de gangsters" (ARON, Raymond. Le Spéctateur Engagé: entretiens avec Jean-Louis Missika et Dominique Wolton, p. 283) -, cf. ARON, Raymond. Paix et Guerre entre les Nations. Paris: Calmann-Lévy, 1962, passim, ou mais sucintamente ARON, Raymond. Le Spéctateur Engagé: entretiens avec JeanLouis Missika et Dominique Wolton, p. 123ss., 215ss., 272, 291, 310).

28 Cf. ARENDT, Hannah. "Totalitarian Imperialism: Reflections on the Hungarian Revolution". In: The Journal of Politics, 20, 1 (Feb. 1958). p. 5-43. 
para quem "[u]ma nova guerra mundial poderia apenas acabar em colapso para o capitalismo ... O socialismo viverá enquanto o capitalismo não perdurará. Pois, a despeito de grandes perdas, a humanidade não apenas sobreviverá, como continuará a se desenvolver." ${ }^{29}$ Ora, diante do prospecto de uma nova guerra mundial, efetivamente atômica, Arendt considera que os riscos envolveriam não apenas o lado capitalista, como Kruschev acreditava, senão ambas partes em conflito e, com uma boa dose de probabilidade, a humanidade como um todo. Para Arendt, portanto,

[s] empre foi um engano mensurar a ameaça do totalitarismo com a régua do conflito relativamente inofensivo entre uma sociedade comunista e [outra] capitalista e não levar em conta a contradição explosiva entre a ficção totalitária e o mundo cotidiano da factualidade no qual vivemos. Mas isso nunca foi tão perigosamente enganador quanto hoje [em dia], quando as mesmas descobertas técnicas, as quais quando consideradas em seu conjunto constituem para nós um mundo factualmente mudado, estão à disposição daqueles que em toda seriedade as consideram como meros meios, isto é, como mecanismos [devices] com os quais se torna real um mundo puramente fictício feito de mentiras e baseado na negação dos fatos. (...) [Pois] o que é uma questão de fato para nós é uma questão de ideologia para a mentalidade totalitária. A questão não está na diferença entre opiniões e convicções básicas, nem nas dificuldades concomitantes de se chegar a um acordo, mas muito mais na aterradora impossibilidade de se concordar acerca de fatos. ${ }^{30}$

O que Hannah Arendt explicita aqui é precisamente o fato de não existir possibilidade de diálogo entre a mentalidade totalitária, para a qual, no caso, o socialismo triunfaria mesmo através do uso de armas nucleares, se necessário, e a mentalidade, senão exatamente "capitalista", pelo menos "ocidental" ou, melhor dito, humana, entendendo-se por esta aquela que levaria em conta, pelo fato mesmo de ser uma "mentalidade alargada" - sendo esta como diz Arendt, "a mentalidade política par excellence", ${ }^{31}$ - o destino da humanidade como um todo. Em outros termos, Arendt critica a cegueira, senão a loucura totalitária, exemplificada na citação de Kruschev, e que estaria disposta a lançar tudo pelos ares em nome de uma suposta vitória final do socialismo sobre o capitalismo; o que os russos e todos aqueles dispostos a fazer uso de armas nucleares não entendem (no caso, não entendiam), contudo, e este é o cerne do

${ }_{29}$ KRUSCHEV apud ARENDT, Hannah. Ibid., p. 19.

30 ARENDT, Hannah. Ibid., p. 21.

31 Cf. ARENDT, Hannah. "Karl Jaspers: A Laudatio". In: Men In Dark Times. New York: Harcourt Brace \& Comapny, 1993. p. 79. 
argumento de Arendt, é que poderia não haver mundo após uma tal vitória nuclear sobre qualquer lado do conflito.

Para Arendt, portanto, era como se o niilismo dos modernos tivesse recebido um implemento sui generis para pôr em prática sua vontade de destruição e, na medida em que esse implemento se tornava uma necessidade em termos do restabelecimento do equilíbrio de forças em termos geopolíticos após a Segunda Guerra mundial (pelo menos o raciocínio era esse), tornava-se necessário repensar, e isto de maneira radical, não apenas as relações internacionais, mas mais fundamentalmente o próprio sentido da política sob o impacto do desenvolvimento das armas nucleares. Este projeto ocuparia Arendt em finais da década de 1950, permanecendo, não obstante, inédito até muito recentemente, quando foi lançado como o ensaio de título "Introdução rumo à política". ${ }^{32}$ Arendt, com efeito, colocava o problema nos seguintes termos:

[n]ossa questão [acerca do sentido da política] surge hoje em dia das experiências muito reais que tivemos com a política; ela é inflamada pelo desastre que a política operou em nosso século e o ainda maior desastre que ameaça emergir da política. Nossa questão é, portanto, muito mais radical, mais agressiva e mais desesperada: ainda possui a política algum sentido?

Colocada desta maneira - e neste momento é assim que ela se coloca para todo mundo - a questão ressoa [a partir de] dois fatores importantes: primeiramente, nossa experiência em relação aos governos totalitários, nos quais a totalidade da vida humana é reclamada a ser tão totalmente politizada que sob eles não há mais nenhuma liberdade de forma alguma. [...] O segundo fato que torna necessária a questão é o monstruoso desenvolvimento dos meios modernos de destruição [...]. Aqui a questão não diz respeito apenas [à questão] da liberdade, senão da própria vida, da existência contínua da humanidade e talvez de toda vida orgânica na terra. A questão que surge aqui torna toda política problemática; ela torna duvidosa se a política e a preservação da vida s[eriam] mesmo compatíveis sob condições modernas $[\ldots] .^{33}$

Logo, é a partir da "dupla ameaça dos estados totalitários e das armas atômicas - uma ameaça apenas tornada pior através de sua conjunção" ${ }^{4}$ - que Arendt visa (re)pensar a política neste seu ensaio, assim como ao longo de sua obra. E no que diz tange especificamente às armas atômicas, Arendt nota que seu desenvolvimento diria respeito

32 Cf. ARENDT, Hannah. "Introduction into Politics". In: ARENDT, Hannah. The Promise of Politics. Ed. J. Kohn. New York: Schocken Books, 2005. p. 93-204.

${ }_{33}$ Ibidem, p. 108-109.

34 Ibidem, p. 111. 
não apenas ao âmbito da tecnologia em sentido estrito, senão que ele teria a ver também com uma espécie de perversão do próprio âmbito político, isto porque em sua visão a esfera pública teria, a partir de finais do século XIX e atravessando o século XX, se tornado uma esfera na qual a força, e não mais o poder - sendo ambos termos entendidos em sentido eminentemente arendtiano, isto é, poder como "habilidade humana não apenas para agir mas para agir em conjunto" 35 e força aqui como o que seria mais tarde tratado em sua obra como "violência" 36 seria sua constante. ${ }^{37} \mathrm{Em}$ outras palavras, para Arendt o surgimento das armas nucleares somente se tornou possível na medida em que, para além das condições estritamente tecnológicas que propiciaram seu desenvolvimento, o próprio raciocínio em política no século XX foi tomado ou pervertido pelos valores da força e/ou da violência, estes, por sua vez, em detrimento do discurso, da racionalidade, em suma, do discurso racional, entendendo-se por este uma forma eminentemente política de ação. ${ }^{38}$

Logo, as armas nucleares seriam para Arendt o retrato fiel de um período que teria supostamente livrado a humanidade (ou uma razoável parte dela) da "força bruta" em termos de suas existências cotidianas; concomitantemente, porém, o conjunto dos estados ocidentais e mais especificamente europeus, a partir do período do imperialismo, teria deslocado a força do espaço privado da casa e da esfera semipública da sociedade para o interior do âmbito eminentemente público da política; nos termos de Arendt,

[p]ara que as pessoas pudessem existir sem [a] força em suas vidas cotidianas, foi necessário haver um aumento na força empregada pela mão pública, pelo estado, cujo uso da força, assim se acreditava, podia ser mantido sob controle posto que ele havia sido explicitamente definido como um mero meio para o fim maior da sociedade, para o livre desenvolvimento de energias produtivas. Nunca ocorreu à mentalidade moderna que os meios da força bruta pudessem eles mesmo se tornar "produtivos" - isto é, que eles poderiam crescer da mesma forma (ou em medida ainda maior) que outras energias produtivas na sociedade - porque a verdadeira esfera de produtividade estava associada à sociedade e não ao estado. (...) Agora sabemos que o contrário foi o que ocorreu. A época considerada como a mais pacífica e menos violenta

35 ARENDT, Hannah. "On Violence". In: ARENDT, Hannah. Crises of the Republic. New York: Harcourt Brace Janovich Publishers, 1972. p. 143.

36 Cf. Ibidem, passim. Vale apontar que Arendt utiliza duas palavras diferentes para "força" em inglês, "force" e "strength".

37 Cf. ARENDT, Hannah. "Introduction into Politics". In: ARENDT, Hannah. The Promise of Politics. Ed. J. Kohn. New York: Schocken Books, 2005. p. 147.

38 Cf. Ibidem, p. 124ss., 146. 
levou diretamente ao maior, ao mais horrendo desenvolvimento dos meios da força. Isto apenas parece ser um paradoxo. O que ninguém havia levado em conta foi a específica combinação de força e de poder que poderia surgir apenas no âmbito público do estado, porque apenas lá as pessoas [men] se juntam e geram poder. ${ }^{39}$

Em outros termos, na medida em que houve uma liberação de forças produtivas da sociedade na modernidade, a forma de sociedade moderna teria deslocado para o âmbito da política aquilo que era até então típico da esfera privada, pré-política. ${ }^{40} \mathrm{~A}$ violência, portanto, de prerrogativa do pater familias, não apenas passava a ser canalizada para a esfera pública, como encontraria nesse processo a revolução tecnológica da ciência experimental moderna. Desse infeliz encontro, por sua vez, surgiriam os prospectos de "guerras totais", isto é, de um tipo de guerra que não pressuporia mais ganhos ou perdas de poder, discussões acerca de limites entre um país e outro, enfim, de todas aquelas questões ligadas à guerra em seu sentido tradicional, leia-se, da guerra como continuação da política através de outros meios (nas famosas ainda que imprecisas palavras de Clausewitz); com o surgimento das armas nucleares, diferentemente, a "guerra pela primeira vez verdadeiramente deixa de ser um meio da política e, como uma guerra de aniquilação, começa a ultrapassar os limites postos pela política e a aniquilar a própria política." 41

Em decorrência desse novo panorama, Arendt se viu forçada a (re)pensar o sentido da política e, assim, veio a entender que a partir da invenção das armas atômicas a questão mais premente de sua época seria aquela acerca do papel que a força deveria ter nas relações internacionais, ou como o seu emprego poderia ser excluído das mesmas. Em outros termos, foi no contexto da guerra fria que Arendt, pensando a questão de uma possível e, tal qual no famoso caso da Baía dos Porcos, em Cuba, provável "guerra total", investigou e refletiu sobre a questão das armas atômicas. E ainda que Arendt não possuísse uma resposta inequívoca para estas indagações eminentemente teóricas - ainda que acerca de temas práticos ou concretos -, resta o fato de que esta linha de abordagem se configura como um dos eixos centrais em termos da reflexão acerca da bomba atômica no pensamento de Hannah Arendt; cabe agora ver quais seriam os outros.

39 Ibidem, p. 149-150.

40 Vale mencionar que Arendt retoma neste ponto suas análises presentes n'A Condição Humana; cf. ARENDT, Hannah. The Human Condition. Chicago and London: University of Chicago Press, 1998. p. 38-49.

41 ARENDT, Hannah. "Introduction into Politics". In: ARENDT, Hannah. The Promise of Politics. Ed. J. Kohn. New York: Schocken Books, 2005. p. 159. 


\subsection{A bomba atômica enquanto artefato científico (ou da relação entre modernidade e ciência experimental)}

Pois para além da linha argumentativa acima investigada e que poderia ser descrita como majoritária dada sua proeminência no pensamento (ou nas obras) de Arendt, há outra linha interpretativa desenvolvida por ela e que já se encontra, ainda que em estado embrionário, no breve artigo de 1954 intitulado "A Europa e a Bomba Atômica". Ali, com efeito, Arendt já aponta ou acena para a tese central (ou pelo menos para parte desta) presente em A Condição Humana; refiro-me à interpretação da bomba atômica como conquista eminentemente tecnológica e, neste sentido, enquanto questão de filosofia da ciência. Seguindo esta linha, pois, Arendt compreende neste ensaio que a bomba atômica sintetizaria o esforço maior, senão o sentido da ciência moderna enquanto meio de se "liberar as forças naturais", 42 tese esta que interessantemente Arendt remete à Goethe no artigo em questão, pois como ela diz, "[t]odos estão inclinados a pensar com o Mephisto de Goethe no Fausto: "Die Elemente sind mit uns verschworen und auf Zerstörung läuft's hinaus" ("Os elementos conspiram conosco e a destruição é a meta"). ${ }^{43}$ Assim, Arendt já ensaiava aqui sua compreensão da importância dos experimentos científicos enquanto repetições humanamente produzidas de processos naturais e nos quais encontrar-se-iam conjugados os "ídolos da era moderna", a saber, "produtividade e criatividade". ${ }^{44}$ Arendt, com efeito, diria mais tarde que, em termos de ciência moderna,

[...] os reais [actual] objetos de conhecimento não podem mais ser coisas ou movimentos eternos, e sim processos, e que o objeto da ciência, portanto, não é mais a natureza ou o universo, mas a história [history], a narrativa [story] do vir a ser da natureza, da vida ou do universo. [...] A natureza, pelo fato de poder ser apenas conhecida através de processos os quais a engenhosidade humana, a engenhosidade do homo faber, podia repetir e refazer no experimento, se tornou um processo, e todas as coisas naturais particulares derivaram seu significado e seu sentido unicamente [a partir] de suas funções no processo mais geral. No lugar do conceito de Ser agora encontramos o conceito de Processo. ${ }^{45}$

\footnotetext{
42 ARENDT, Hannah. "Europe and the Atom Bomb". In: ARENDT, Hannah. Essays in Understanding: 1930-1954. Ed. J. Kohn. New York: Schocken Books, 1994. p. 419.

43 Ibidem, p. 419. O editor, contudo, aponta que Arendt provavelmente citava de cabeça, no que ela trocou a palavra "aniquilamento" no original [Vernichtung], por "destruição".

44 Cf. ARENDT, Hannah. The Human Condition. Chicago and London: University of Chicago Press, 1998. p. 295-296.

45 Ibidem, p. 296.
} 
Sendo a tese central d'A Condição Humana aquela que vê no coração do projeto da modernidade o conceito de Processo - com "p" maiúsculo, como citado na última sentença da passagem acima, sendo também que este termo representaria ou sintetizaria a liberação de energias produtivas nas sociedades contemporâneas, ditas também de consumo -, a bomba atômica, ou de maneira mais geral, a tecnologia de fissão nuclear não tinha como não chamar a atenção de Arendt enquanto filósofa da ciência. Não obstante, se em seu artigo sobre a bomba atômica Arendt ainda vê analogias entre esta e a liberação de forças naturais típica da ciência moderna, mais tarde ela refinaria essa interpretação, chegando, pois, à noção da bomba atômica não mais como "uma questão de desencadear e liberar processos elementares naturais, mas de manejar na terra e na vida cotidiana energias e forças as quais ocorrem somente fora da terra, no universo; isto já é feito, embora apenas nos laboratórios de pesquisa de físicos nucleares." 46

Em outros termos, a partir de sua obra A Condição Humana, publicada em 1958, Arendt passa a reconhecer nas teorias físicas que propiciaram a tecnologia para se produzir o artefato da bomba atômica uma "mudança de escala" em relação à ciência moderna - iniciada fundamentalmente com Galileu e Copérnico -, posto que a bomba atômica visaria liberar, como disse em certo momento o presidente dos Estados Unidos Harry Truman, aquele mesmo que ordenou seu lançamento, "[a] força a partir da qual o sol deriva seu poder". ${ }^{47}$ Neste sentido, a bomba atômica estaria para nossa época tanto quanto as astronaves a levar o ser humano à lua ou ao espaço, dado que ambas tecnologias pressuporiam a imensa conquista intelectual ou teórica - ainda que de efeitos nefastos - do "ponto (de vista) de Arquimedes", isto é, a maneira de agir na terra como se dispuséssemos da natureza terrestre desde seu exterior. ${ }^{48} \mathrm{E}$ pelo fato de basear-se não mais em uma ciência de ordem "natural", e sim de ordem "universal", ${ }^{49}$ a tecnologia nuclear implicaria um grau de alienação do ser humano

46 Ibidem, p. 150.

47 A frase completa é: "The force from which the sun drives [sic] its power has been loosened against those who brought war to the Far East [a força a partir da qual o sol deriva seu poder foi solta contra aqueles que levaram a guerra ao extremo oriente]" (TRUMAN apud DEMENCHONOK, Edward. "Introduction: From Power Politics to the Ethics of Peace". In: DEMENCHONOK, Edward. (Ed.). Philosophy after Hiroshima. Cambridge: Cambridge Scholars Publishing, 2009. p. 5. No original o verbo "derivar" [derive] está grafado como "drive" [dirigir], o que não faz sentido).

48 Cf. ARENDT, Hannah. The Human Condition. Chicago and London: University of Chicago Press, 1998. pp. 257ss., assim como, da mesma autora, "The Conquest of Space and the Stature of Man". In: ARENDT, Hannah. Between Past and Future. Penguin Books, 2006. p. 260-274.

49 Cf. ARENDT, Hannah. "The Conquest of Space and the Stature of Man". In: ARENDT, Hannah. Between Past and Future. Penguin Books, 2006. p. 272. 
em relação ao próprio ambiente sumamente perigoso. Para Arendt, portanto, o que estava implícito nas teorias que propiciaram a construção das armas atômicas era o sentido de distanciamento ou de alienação do ser humano a respeito do próprio mundo e, em última análise, de si mesmo, posto que tais experimentos - ainda que ela, seguindo seu antigo companheiro, Günther Anders, para o qual a bomba atômica não poderia de fato ser denominada de experimento propriamente dito, não utilizasse mais tampouco tal terminologia ${ }^{50}$ - somente ter-se-iam tornado possíveis a partir do momento em que linguagens cada vez mais abstratas e apartadas do mundo do "senso comum" humano se tornaram imprescindíveis em termos da constituição das ciências físicas no século XX. Em suma, Arendt percebia uma relação intrínseca entre o afastamento radical da ciências físicas no XX em relação ao mundo tal qual percebido pelos sentidos e o desenvolvimento de tecnologias que visavam reproduzir na superfície da terra efeitos existentes apenas fora do globo terrestre e que, por isso mesmo, não podiam nem mesmo ser concebidos em linguagem humana. Cabe agora ver como é que, em termos concretos, tal alienação cobraria seu preço em termos positivos para Arendt.

\section{Os herdeiros da bomba atômica: reflexões sobre a situação contemporânea}

Vimos que existem duas linhas interpretativas principais no pensamento de Hannah Arendt no que diz respeito seja ao surgimento, seja ao uso efetivo da bomba atômica e/ou da energia atômica em seu sentido mais amplo. Em outros termos, Arendt debruçou-se sobre a questão da bomba atômica tanto em termos de análise realista das relações internacionais quanto em termos de filosofia da ciência. E no que diz respeito a este último viés, algumas questões éticas surgiram no processo, as quais, por sua vez, tinham a ver fundamentalmente com a alienação crescente trazida para dentro da vida cotidiana das pessoas na modernidade, isto, por sua vez, como efeito das sucessivas revoluções científicas tais quais os últimos séculos têm testemunhado.

Em termos cronológicos, a abordagem arendtiana da questão da bomba atômica parece ser algo eminentemente ligado, senão circunscrito, aos seus escritos de meados para finais da década de 1950; não obstante, a partir de finais da década de 1960, isto é, a partir das revoluções estudantis que viriam a varrer boa parte do mundo ocidental

50 Cf. ARENDT, Hannah. The Human Condition. Chicago and London: University of Chicago Press, 1998. p. 150, n. 13. 
e que viriam a ficar gravadas sob a rubrica do "Maio de 68", Arendt viria a retomar essa problemática, ainda que de maneira extremamente oblíqua, posto que neste momento a bomba atômica aparece a partir de seus efeitos psicológicos e, mais especificamente, junto a uma geração que, ainda que não tivesse passado pelos horrores da guerra, viveu suas consequências. Tudo isso para dizer que Arendt interpretaria as revoltas estudantis como sendo, em parte pelo menos, uma espécie de resposta ao terror psicológico da era da bomba atômica, em seus contornos mais amplos. Logo, Arendt, ao analisar as revoltas estudantis, ligou a fúria aparentemente niilista dos estudantes das mais variadas partes do globo, ou mais exatamente a apropriação, por parte destes jovens, de um tipo de discurso ideológico de "glorificação da violência (...), esta nova guinada para a violência no pensamento dos revolucionários", 51 precisamente à experiência concreta vivida após o lançamento das bombas sobre Hiroshima e Nagasaki, assim como ao clima de constante medo de uma guerra nuclear bastante presente no contexto da guerra fria. Assim, Arendt estabelece um nexo causal entre estes fatores, pois como ela coloca a relação,

[o] pathos e o élan da Nova Esquerda [New Left], sua credibilidade, por assim dizer, estão intimamente ligados ao maluco desenvolvimento suicida de armas modernas; esta é a primeira geração a crescer sob a sombra da bomba atômica. Eles herdaram da geração de seus pais a experiência de intrusão maciça de violência criminosa na política: eles aprenderam na escola superior e na faculdade sobre os campos de concentração e de extermínio, sobre a matança completa de civis na guerra sem as quais as operações militares modernas não são mais possíveis mesmo quando restritas à armas 'convencionais'. ${ }^{52}$

Aquilo que, na minha opinião, merece ser ressaltado nessa interpretação e, mais exatamente, na citação acima, é a frase sobre "a experiência de intrusão maciça de violência criminosa na política", ${ }^{53}$ a qual resume muitíssimo bem o teor da investigação incessante da parte de Arendt acerca do sentido da política em pleno século XX, um século que, como ela mesma disse, citando Lênin, na verdade, teria sido de

51 ARENDT, Hannah. "On Violence". In: ARENDT, Hannah. Crises of the Republic. New York: Harcourt Brace Janovich Publishers, 1972. p. 114-115.

52 Ibidem, p. 115-116.

53 Com efeito, Arendt diz que "[é] apenas natural que a nova geração deva viver mais atenta à possibilidade do dia final [doomsday] do que aqueles 'acima de trinta [anos]', não porque eles são mais jovens mas porque esta foi sua primeira experiência decisiva no mundo. (...) Se você perguntar a um membro desta geração duas questões simples: 'Como você quer que o mundo seja daqui a cinquenta anos?' e 'Como você quer que a sua vida seja daqui a cinco anos?' as respostas s[eriam] freqüentemente precedidas por 'Desde que haja um mundo' e, 'Desde que eu esteja vivo'." (Ibidem, p. 119-120). 
"guerras e revoluções, consequentemente, um século daquela violência que é atualmente acreditada como sendo seu denominador comum." 54 Não obstante, Arendt, na medida em que veio a falecer em 1975, não pôde presenciar alguns acontecimentos que mudariam (em alguma medida) o panorama político internacional, e é com isto em mente que encerrarei minha discussão.

Em primeiríssimo lugar, Arendt não presenciou o fim da guerra fria, ainda que estejamos a ver o renascimento de um novo expansionismo russo, ou mesmo chinês, como se pode ver nas disputas por determinadas ilhas (Senkaku, notadamente, atualmente em posse do Japão), assim como por novas delimitações marítimas no assim chamado mar do sul da China. E se, por um lado, a cessação da guerra fria, para não falar em seu resfriamento, trouxe ao globo a sensação de (alguma) tranquilidade no que tange ao uso de armas nucleares, resta o fato preocupante de que tais armas ainda estão aí. Com efeito, não se deve esquecer que desde meados da década de 1970 (quando Arendt faleceu), um número maior de países ascendeu ao posto de detentores da capacidade científica (leia-se enriquecimento de urânio ou de plutônio) para a produção de armas nucleares, ou seja, o seleto clube dos facínoras em potencial, dos suicidas em escala planetária, apenas aumentou (sem contar o elemento fundamentalista-religioso nesta mistura...). ${ }^{55}$ Por outro lado, acidentes em usinas nucleares, notadamente em Three Mile Island (EUA, 1979), Chernobyl (na Ucrânia, então parte do bloco da URSS, em 1986) e, mais recentemente no ano de 2011 em Fukushima, no Japão, fizeram acender a luz vermelha em termos da catástrofe que apenas parece adormecida.

E se Arendt, em 1958, escreveu um livro inteiro de forma a alertar aqueles que quisessem ouvi-la sobre a imensa, assim como inaudita liberação de processos vitais no interior das sociedades modernas, no que estas consolidar-se-iam sob a forma revolucionária da sociedade de consumo, o que não diria ela, míseros cinquenta e seis anos mais tarde, de uma sociedade, tal qual a chinesa, que comporta cerca de um bilhão, trezentos e cinquenta milhões, mais os seus muitos milhares de habitantes? Isto sem falar em sua forma de estado, no mínimo tirânica, senão totalitária... ${ }^{56}$ Diante destes desenvolvimentos - sendo que a China vem acompanhada de uma Índia, sendo esta outra gigantesca sociedade a engatinhar rumo ao Processo (incrustado no cerne) do Consumo e às armas nucleares, de uma Rússia expansionista etc. -, é como se os prognósticos ou temores de Arendt não fossem senão um

54 Ibidem, p. 105.

55 Cf. <http://en.wikipedia.org/wiki/List_of_states_with_nuclear_weapons>.

56 Algumas indicações neste sentido são dāà pelā própria Arend̄t; cf. ARENDT, Hannah. The Origins of Totalitarianism. New York: Schocken Books, 2004. p. 392. 
mero ensaio para a encenação verdadeira a ocorrer a partir do século XXI. É preciso reconhecê-lo: o nillismo, ${ }^{57}$ em suma, mal parece ter começado...

\section{Referências}

ARENDT, Hannah. "Totalitarian Imperialism: Reflections on the Hungarian Revolution". In: The Journal of Politics, 20, 1 (Feb. 1958), p. 5-43.

. "On Violence". In: ARENDT, Hannah. Crises of the Republic. New York:

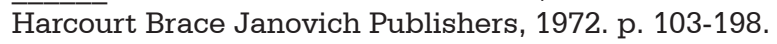

. "Karl Jaspers: A Laudatio". In: Men In Dark Times. New York: Harcourt Brace \& Comapny, 1993. p. 71-80.

. "Europe and the Atom Bomb". In: ARENDT, Hannah. Essays in Understanding: 1930-1954. Ed. J. Kohn. New York: Schocken Books, 1994. p. 418-422. 1998.

. The Human Condition. Chicago and London: University of Chicago Press,

. "Personal Responsibilty Under Dictatorship". In: ARENDT, Hannah. Responsibility and Judgment. Ed. J. Kohn. New York: Schocken Books, 2003. p. 17-48.

. “Collective Responsibility". In: ARENDT, Hannah. Responsibility and Judgment. Ed. J. Kohn. New York: Schocken Books, 2003. p. 147-158.

. The Origins of Totalitarianism. New York: Schocken Books, 2004.

. "Introduction into Politics". In: ARENDT, Hannah. The Promise of Politics. Ed. J. Kohn. New York: Schocken Books, 2005. p. 93-204.

. "The Conquest of Space and the Stature of Man". In: ARENDT, Hannah. Between Past and Future. Penguin Books, 2006. p. 260-274.

ARON, Raymond. Paix et Guerre entre les Nations. Paris: Calmann-Lévy, 1962.

. Le Spéctateur Engagé: entretiens avec Jean-Louis Missika et Dominique Wolton. Paris: Julliard, 1983.

CAMUS, Albert. "Actuelles I (Chroniques 1944-1948)". In: CAMUS, Albert. Essais. Ed. R. Quilliot. Paris: Gallimard, 1965. p. 291-293.

DEMENCHONOK, Edward. "Introduction: From Power Politics to the Ethics of Peace". In: DEMENCHONOK, Edward. (Ed.). Philosophy after Hiroshima. Cambridge: Cambridge Scholars Publishing, 2009. p. 1-40.

GAY, William C. "Nuclear Weapons and Philosophy in the Twenty-First Century: The Relevance of Initial Philosophical Responses to the Atomic Bomb". In: DEMENCHONOK, E. (Ed.). Philosophy after Hiroshima. Cambridge: Cambridge Scholars Publishing, 2009. p. 43-68.

57 Vale explicitar que Arendt não parece ter sido grande apreciadora do termo, ainda que ela o utilizasse parcimoniosamente; com efeito, n'As Origens do Totalitarismo a metáfora principal a sintetizar o niilismo desse sistema político é a do "turbilhão"; n'A Condição Humana ela fala, sobretudo, em termos de "alienação" etc. 
G. G. Rossatti - Hannah Arendt e a filosofia política na era atômica

JASPERS, Karl. Die Atombombe und die Zukunft des Menschen. München: Piper Verlag, 1958.

\section{Endereço postal:}

Programa de Pós-Graduação em Filosofia - UFSM

Av. Roraima, 1000, prédio 74-A, sala 2308

Santa Maria, RS, Brasil

Data de recebimento: 01-08-2016

Data de aceite: 06-12-2016 